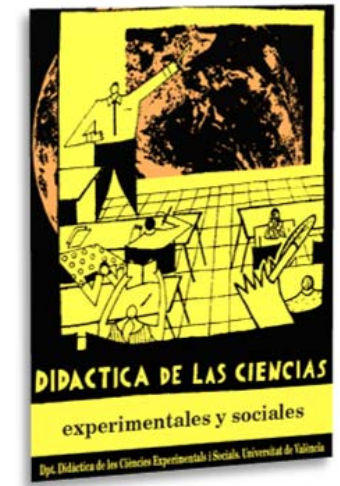

\title{
Educación para la Ciudadanía en España. Una asignatura para la confrontación ideológica y política
}

\author{
Citizenship Education in Spain. A subject for \\ ideological and political confrontation
}

DOI:10.7203/DCES.37.14318

\author{
A. Ernesto Gómez Rodríguez \\ Universidad de Málaga, aegomez@uma.es \\ ORCID iD: http://orcid.org/0000-0001-7376-4536 \\ Carmen Rosa García-Ruiz \\ Universidad de Málaga, crgarcia@uma.es \\ ORCID iD: http://orcid.org/0000-0002-7937-8131
}

\begin{abstract}
RESUMEN: En España vivimos una de las cuestiones más controvertidas de la educación por la implantación de Educación para la Ciudadanía y los Derechos Humanos, una materia escolar recomendada reiteradamente por la Unión Europea y organismos internacionales. Esta polémica trascendió lo educativo al responder a una estrategia política revestida de argumentos religiosos basados en axiomas profundamente antidemocráticos. La presente investigación utiliza el método histórico aplicado al análisis del currículo. La documentación utilizada procede, principalmente, de la prescripción curricular, fuentes hemerográficas y judiciales. Su análisis ha permitido centrarnos en cómo los colectivos más tradicionales de la sociedad utilizaron el espacio público para perpetuar su poder y control, frenando cambios en el currículo y en la práctica educativa. El artículo pretende evidenciar la existencia de una concatenación de acciones perfectamente acompasadas y secuenciadas con la intención de obstaculizar la implantación de la materia y mantener la hegemonía de unos particulares valores religiosos por encima de los civiles. Una confrontación latente que espera su reactivación.
\end{abstract}

PALABRAs Clave: educación para la ciudadanía, ciencias sociales, currículo, problemas controvertidos, valores religiosos

ABSTRACT: In Spain, we are lived one of the most controversial issues in education because of the implementation of Education for Citizenship and Human Rights, a school subject recommended repeatedly by the European Union and international organizations. The controversy went beyond education due to a planned political strategy covered by religious arguments based on deeply undemocratic axioms. This research uses the historical method applied to the analysis of the curriculum. The documentation used comes, mainly, from curriculum prescription, newspapers, and judicial sources. Their analysis has allowed us to focus on how the most traditional and conservative groups of our society used public space to perpetuate their power and control, slowing down changes in the curriculum and educational practice. The article aims to demonstrate the existence of a concatenation of perfectly coordinated and sequenced actions with the clear intention of hindering the implementation of the subject and maintaining the hegemony of particular religious values over civil ones. A latent confrontation awaiting its reactivation.

KEYWORDS: citizenship education, social studies, curriculum, controversial issues, religious values

Fecha de recepción: abril de 2019 Fecha de aceptación: septiembre de 2019 


\section{CONTEXTO Y JUSTIFICACIÓN DE LA INVESTIGACIÓN}

El tema a investigar surge del interés por los cambios en el curriculum social o las dificultades para alcanzar un pacto por la educación, vividos entre 2006 y 2013, y no pueden entenderse sin interpretarlos en el contexto de la división política, social y cultural de nuestro país. Pretendemos abordar cómo se gestó la polémica en torno a la materia Educación para la Ciudadanía y los Derechos Humanos, desde su introducción hasta su supresión del curriculum escolar.

Los objetivos de la investigación se centran en:

- Conocer los discursos esgrimidos por los agentes que generaron y alimentaron la polémica, y las estrategias llevadas a la práctica.

- Entender cómo los colectivos más conservadores de nuestra sociedad ganaron la batalla mediática contra la materia.

El marco teórico de referencia para esta investigación parte de las aportaciones que otras ciencias de la educación proporcionan a la comprensión del curriculum social. Hemos contemplado la apuesta por un análisis del curriculum como construcción sociohistórica realizado por Romero y Luis (2003); especialmente su referencia a Young (1971). Perspectiva relevante para focalizar nuestro interés en aquellos agentes sociales que frenan los cambios curriculares para preservar su poder y control sobre el mismo.

También hemos seguido el análisis en clave histórica, social y cultural, de los conflictos en torno al curriculum de los Social Studies en EE.UU. (Evans, 2004). Las reiteradas polémicas generadas en ese contexto, tienen de común con el tema que abordamos el que hayan sido alimentadas en el debate público no experto, adquiriendo una acentuada dimensión política e ideológica, reflejando una profunda división cultural de aquella sociedad a lo largo de un siglo. La interpretación de esa circunstancia es que los contínuos cambios en su curriculum, han consolidado el papel de las disciplinas y reducido su identidad de conocimiento escolar integrador que se genera en torno al tratamiento de cuestiones sociales relevantes.

Consideramos que, conocer la naturaleza de los conflictos generados en la definición del curriculum y las ideologías en conflicto, permitirá tomar conciencia al profesorado de los factores que condicionan su práctica educativa y elaborar criterio docente en la medida en que se quiera que sea emancipadora y permita articular un discurso público que refuerce su rol en la sociedad.

El diseño metodológico se ha realizado a partir del tema a investigar, conectando con los intereses habituales en nuestro ámbito de conocimiento y su tarea fundamental, la formación del profesorado para la enseñanza de contenidos sociales. Su naturaleza y marco teórico de referencia, conlleva un diseño metodológico abierto, acotado cronológicamente, y con una recogida de datos en aquellas fuentes que permiten reconocer a los agentes activos en la polémica para esbozar cómo configuraron y construyeron una realidad conflictiva que encierra un problema de mayor calado, la apuesta por un modelo de sociedad uniforme o plural.

La documentación utilizada procede principalmente de la prescripción curricular, fuentes hemerográficas y judiciales que manifestaron las discrepancias y arrojaron datos que han sido tratados para diseñar el escenario de la polémica y analizar los factores que la configuraron.

\section{DEBATE O CONFRONTACIÓN. LA RAÍZ DE LA POLÉMICA}

En anteriores trabajos, dudamos de la implantación de la materia EpC y la deriva academicista que podría adquirir (Gómez, 2008), en la misma medida que el debate generado formaba parte de un plan diseñado para retrasar e impedir su implantación (Gómez y García, 2013); circunstancias que ahora pretendemos mostrar con mayor claridad.

Entre 2004 y 2014 se dió una confrontación ideológica y política que terminó eliminando la Educación para la Ciudadanía y los DD.HH. (en adelante EpC) del sistema educativo. La secuencia de los hechos comenzó a modo de debate, deformado por una cuestión de carácter ideológico 
(Cámara, 2009). Autores como Fernández-Soria (2008) o Savater (2007) apuntaron desde el principio que el propósito final de sus detractores era encumbrar la fe religiosa por encima de la libertad cívica, para recuperar la potente presencia de la Iglesia Católica en nuestra sociedad.

Paradógicamente, fueron los sectores ideológicos que monopolizaron la enseñanza durante el franquismo, imponiendo sus valores y principios, los menos dispuestos a permitir que en las aulas entraran ideas y valores diferentes a las suyas, ni siquiera aquellos que acordes con el espíritu de la Constitución, defienden la libertad de pensamiento, el razonamiento crítico y el derecho a la libre toma de decisiones de las personas.

La polémica comienza en 2004, tras ganar el PSOE las elecciones y cumplir su promesa electoral de frenar la reforma educativa del gobierno del PP (Ley Orgánica de 2002), que debía entrar en vigor en el curso escolar 2004-2005.

En breve tiempo, el gobierno resultante de las urnas presentó una propuesta Ministerio de Educación y Ciencia (MEC, 2004) con las líneas generales de su futura Ley. En el capítulo Los valores y la formación ciudadana contemplaba que, en una sociedad democrática, la educación en valores debe referirse a aquellos que capacitan para el desarrollo de la ciudadanía, qué actitudes de respeto, tolerancia, solidaridad, participación o libertad deben figurar entre los objetivos y las tareas del sistema educativo. Esto abrió un debate en el que participaron numerosas asociaciones y organizaciones, pero desde el primer momento surgió la polémica, pues la pretensión del Ministerio de introducir una materia o área educativa destinada a abordar la educación en valores, activó alarmas y protestas entre los sectores más conservadores de la sociedad.

Aprobada la Ley Orgnánica de Educación (LOE, 2006), el PP, sin asumir su derrota electoral, encontró en la nueva materia el instrumento ideal para desestabilizar al gobierno socialista. Tras anunciar su rechazo a la nueva materia, cedió el protagonismo en la confrontación a organizaciones pilotadas por la Iglesia Católica, pero no elevó recurso ante el Constitucional, pues su implantación respondía a una recomendación supraestatal emitida por el Parlamento Europeo y aprobada en 2003, con el apoyo del gobierno español del PP.

\subsection{Las recomendaciones europeas a favor de la EpC}

En 1997, siendo Ministra Esperanza Aguirre, la Declaración de Jefes de Estado y de Gobierno del Consejo de Europa proclamó la EpC como prioridad de su proyecto político y educativo, con la finalidad de ayudar a participar activamente en sociedad, desde la práctica de derechos y deberes. Tenía dos objetivos prioritarios: elevar la conciencia de cómo la educación puede contribuir a desarrollar la ciudadanía y la participación democrática y promover la cohesión social y el entendimiento intercultural, el respeto de la diversidad y de los derechos humanos. Pretendía fortalecer la capacidad de los estados miembros para hacer de la EpC Democrática un objetivo prioritario de la política educativa.

Con Rajoy de Ministro, el Comité de Ministros de la UE adoptó la Declaración y el programa sobre la EpC Democrática y en 2000, la XX $X^{a}$ Sesión de la Conferencia Permanente de Ministros Europeos de Educación, siendo Ministra Pilar del Castillo, aprobó los resultados y conclusiones del Proyecto de EpC Democrática.

Gobernando ya el PSOE, siendo San Segundo Ministra, el Consejo de Europa declaró el 2005, Año Europeo de la Ciudadanía a través de la Educación. La UE calificaba el desarrollo de la ciudadanía europea como una de sus principales prioridades de acción, y patrocinaba el estudio de la organización de la EpC en los 30 países europeos que integran la Red Europea de Información en Educación (EURYDICE, 2005, 8).

\subsection{La EpC y los DD.HH. en la Ley Orgánica de Educación}

En su Exposición de Motivos, la LOE señalaba sobre la nueva materia: 
Su finalidad consiste en ofrecer a todos los estudiantes un espacio de reflexión, análisis y estudio acerca de las características fundamentales y el funcionamiento de un régimen democrático, de los principios y derechos establecidos en la Constitución española y en los tratados y las declaraciones universales de los derechos humanos, así como de los valores comunes que constituyen el sustrato de la ciudadanía democrática en un contexto global (BOE 106, 2006).

En ningún caso consideraba los contenidos de la EpC alternativos o sustitutorios de la enseñanza religiosa, ni que entrasen en contradicción con la práctica democrática que debía inspirar el conjunto de la vida escolar y que habría de desarrollarse como parte de la educación en valores con carácter transversal a todas las actividades escolares.

En diciembre de 2006 y noviembre de 2007 se publicaron los Reales Decretos que establecían las enseñanzas mínimas de Educación Primaria, ESO y Bachillerato, implantando un conjunto de asignaturas escolares con tres denominaciones diferentes:

\begin{tabular}{l|l|l|}
\hline Educación para la Ciudadanía y los DD.HH. & $4^{\circ}$ o $5^{\circ}$ Educación Primaria & art. 18.3 \\
\hline & $1^{\circ}$ a $3^{\circ}$ ESO & art. 24.3 \\
\hline Educación ético-cívica & $4^{\circ}$ ESO & art. 25.1 \\
\hline Filosofía y ciudadanía & $1^{\circ}$ o $2^{\circ}$ Bachillerato & art. 34.6
\end{tabular}

Configuradas en torno a cuatro bloques temáticos (BOE 5, 2007):

1) Convivencia con el entorno próximo

2) Principios de vida en una sociedad democrática

3) Ejercicio de la ciudadanía en un contexto global

4) Situación, y relación del individuo consigo mismo y con los demás

Pronto, el bloque que concernía a la educación afectiva, vinculado al objetivo de "favorecer el desarrollo de personas libres e íntegras a través de la consolidación de la autoestima, la dignidad personal, la libertad y la responsabilidad”, se convirtió “en el sujeto de la discordia” (García, 2007); y el epígrafe dedicado a la familia sería uno de los pilares fundamentales de la controversia suscitada; la más virulentas de los últimos años en el ámbito educativo (Valencia, 2013).

\section{LA PARTICIPACIÓN ACTIVA DE LA IGLESIA CATÓLICA}

Desde organizaciones adscritas a la Iglesia Católica, surgieron iniciativas alentadas por algunos medios de comunicación que configuraron una potente plataforma mediática que desencadenó una ruidosa campaña articulada en torno a cuatro premisas que expertos y sentencias judiciales han desmontado reiteradamente (Blanco y García, 2007):

a) Negar la capacidad del Estado para impulsar y promover la formación en valores democráticos, entendiendo que éste es un derecho y privilegio exclusivo de la familia.

b) Criticar la introducción de una asignatura obligatoria cuyos principios suplantaban el papel de la enseñanza de la Religión (Rouco, 2007).

c) Defender la capacidad legal de las familias para oponerse al Estado, en aras a la libertad de enseñanza, ideológica, religiosa y de culto (art. 27 de la Constitución).

d) Convencimiento de que mediante la nueva materia escolar se pretendía imponer, la educación en la "ideología de género" y "relativismo ético". 
La autoría de estas premisas era de Profesionales para la Ética (2009) que marcó el rumbo de los argumentos y acciones a seguir y que la Iglesia Católica adoptó contra la materia. Durante el proceso negociador de la LOE, la plataforma anti EpC convocó numerosos actos públicos que culminaban en manifestaciones encabezadas por la jerarquía católica y arropadas por la derecha política, instrumentalizándola electoralmente.

Mientras, los sectores laicos ofrecieron una tibia respuesta; no todos apoyaban su implantación y entre los que lo hacían no había consenso; las federaciones de madres y padres progresistas la apoyaban, pero los sindicatos docentes discrepaban respecto a su presencia en el currículo, su carácter trasversal o específico, el contenido, lo reducido de su horario, el profesorado competente de impartirla, etc.

El profesorado de Filosofía fue muy reticente, al considerar que EpC desvirtuaba y disminuía su carga lectiva. Para sectores más radicales, la materia suponía un avance insuficiente al no suprimir la asignatura de Religión; una medida inviable sin la revisión del Concordato firmado con la Santa Sede en 1978. Cuando el MEC, para concitar apoyos de los sectores católicos moderados, permitió adaptar la EpC a los idearios de los centros católicos, aumentó los recelos de este sector, restando sus apoyos.

Las divergencias en el ámbito laico se prodigaron en la Iglesia Católica; sus jerarquías desempeñaron un importante papel en la polémica con pronunciamientos, personales e institucionales. Desde asociaciones y grupos cristianos de base se apoyaba su impartición, entendiendo que sus contenidos no violentaban ni la conciencia, ni la libertad del alumnado. Intelectuales y expertos educativos cristianos se implicaron en el diseño de textos de EpC. José Antonio Marina y Carmen Pellicer, dirigieron los de SM y Santillana. Pero el conflicto tuvo mayor trascendencia cuando los sectores fundamentalistas del episcopado se enfrentaron a grupos como la Federación Española de Religiosos de la Enseñanza.

También hubo divergencias entre la Federación Española de Religiosos de Enseñanza (FERE) y la Confederación Católica de Padres de Alumnos (CONCAPA); estos abogaban por promover la objeción de conciencia y los primeros defendían posiciones más contemporizadoras. Manuel de Castro, secretario de FERE, rechazaba que EpC fuese un catecismo socialista y afirmaba que aprobada la Ley, como demócratas, su obligación era aceptarla. Carbonell, el dirigente de la CONCAPA, equiparaba la nueva materia con la Formación del Espíritu Nacional impartida durante el franquismo (Garrido, 2007).

En síntesis, la Iglesia desvelaba su irresuelta relación con el Estado, además del enfrentamiento entre dos visiones sobre la educación, la conservadora-clerical y la progresista-laica (Hernández, 2009).

\section{LA INTERVENCión de LAS COMUNIDAdES AUTÓNOMAS}

Desatada la polémica sobre la EpC en los medios de comunicación, tocó intervenir a los gobiernos autonómicos. Las comunidades gobernadas por el PP adoptaron medidas para retrasar, impedir o transformar la materia (Castilla y León, País Valenciano, Madrid, La Rioja y Murcia). Otras como Galicia y Baleares, al perder el gobierno el PP las derogaron. Navarra, donde la Iglesia tiene fuerte arraigo y gobernaba la derecha, mantuvo una postura independiente. En los primeros momentos, la oposición institucional no tuvo plan prefijado, actuando cada autonomía de manera descoordinada.

El primer paso consistió en introducir modificaciones en el currículo, como se apuntaba desde la Comunidad de Madrid:

[...] las Comunidades del PP tenemos lógicamente la obligación de acatar la Ley, pero como precisamente deja importantes competencias a las Comunidades Autónomas a la hora de 
elaborar los planes de estudio, los currículos, pues nos hemos puesto de acuerdo en tener unas enseñanzas comunes (Peral, 2007, 15).

Se suprimían los aspectos más discutidos: las cuestiones de género o los modelos de familia. El MEC recurrió tales decisiones y comenzaron los contenciosos administrativos que le fueron dando la razón.

El segundo paso consistió en retrasar su implantación; dado que las autonomías podrían implantar su enseñanza los cursos 2007-08 o 2008-09. Como el PP confiaba ganar las elecciones de 2008 y reestablecer la derogada LOCE, en las Comunidades que gobernaba retrasó su implantación (Peral, 2007, 15-16).

\section{LA INSTRUMENTALIZACIÓN DE LOS LIBROS DE TEXTO DE EPC}

En la siguiente fase se reforzó la crítica y los argumentos contrarios a la EpC. Papeles FAES (2007), publicó un sesgado "estudio” de los manuales, que aún se estaban redactando, extrapolando y destacando las cuestiones más llamativas y escabrosas: familia, matrimonios gays y cuestiones de género. Aportó argumentos para que los medios de comunicación resaltaran la oposición a la materia, transmutando su sentido: adoctrinar al alumnado en una ideología antioccidental, antiamericana y estatalista. El texto más difundido y al que más se desvirtuó su contenido, aún cuando no estaba concebido como manual, fue el de la editorial Akal, "Educación para la Ciudadanía. Democracia, capitalismo y estado de derecho”.

Desde la Universidad San Pablo-CEU, Escandell (2009) realizó otro estudio que volvía a mostrar el origen viciado de las conclusiones, al negar a las editoriales la capacidad para acometer su trabajo sin el control y directriz de la Iglesia. Rechazaba por inadecuados, nocivos y peligrosos los textos de las editoriales católicas, alegando que podían ser peores que otros y confundir al alumnado. Quedó manifiesto el malestar de la Conferencia Episcopal con algunas de estas editoriales, especialmente con SM, a la que llegó a amenazar con retirar su carácter cristiano por editar un texto para enseñar religión musulmana.

Sin embargo, otros trabajos que los analizaron como creación cultural de la materia, han puesto de manifiesto la tendenciosidad y falta de rigor de tales análisis. El primero fue Jares (2008), quién afirmó que respondían a meros estereotipos y se basaban en las temáticas escabrosas antes citadas. García y Gómez (2012) llegaron a similares conclusiones tras analizar diecisiete manuales de las editoriales de mayor difusión. Por su parte, Carrillo (2011) realizó un análisis del tratamiento de los valores en los textos de EpC de Cataluña, con parecidos resultados. Finalmente, la tesis doctoral de González (2011) refrendó que los manuales utilizados no eran "tendenciosos y adoctrinadores” como sostenían sus detractores.

\section{LA POLÉMICA EN EL ÁMBITO JUDICIAL}

El siguiente paso, se relacionaba con la vía administrativa y judicial. Los detractores de la materia presentaron recursos administrativos para frenar y retrasar su implementación. Se anunció la formulación de miles de recursos presentados ante las autoridades educativas de las CC.AA. gobernadas por socialistas, por familias que rechazaban que sus hijos fuesen adoctrinados en una ideología totalitaria. Como aquellas no accedían a sus peticiones de admitir que sus hijos no cursasen la asignatura, se cambió de táctica.

$\mathrm{Al}$ amparo del artículo 16.1 de la Constitución que garantiza la libertad ideológica, religiosa y de culto de los individuos y las comunidades, se animó a las familias a recurrir ante los Tribunales Superiores de sus CC.AA., alegando la objeción de conciencia para sus hijos y reclamando el derecho a no cursar las asignaturas. 
Muchos juristas encontraron graves problemas en la utilización de esta vía. Al insertarse la EpC en la categoría de una Ley estatal, sólo la podría derogar el Tribunal Constitucional y no por tribunales de menor rango como los Superiores de las Comunidades ${ }^{1}$. También en el hecho de que en un Estado de Derecho, una vez que se ha aprobado una ley, es obligado su cumplimiento y, como un experto constitucionalista señaló, (Carrillo, 2008) llamar a la objeción, es incitar a la desobediencia legal, siendo una invocación abusiva, desproporcionada y sobre todo improcedente.

Las primeras resoluciones supusieron un quebranto para los recurrentes, ya que los Tribunales Superiores dictaminaron que la EpC se impartiese en el primer curso escolar de su aplicación, negando la capacidad para alegar objeción de conciencia; pero la presión no cedió y se siguieron presentando recursos.

En Andalucía, se había optado por aceptar íntegramente el currículo de EpC propuesto por el MEC. Sin embargo, el Tribunal Superior de dicha CC.AA., dictaminó que se rectificase y se admitiese la objeción de las familias porque la nueva materia empleaba conceptos de indudable trascendencia ideológica y religiosa como la ética, la conciencia moral o los conflictos morales.

Contra lo dictaminado por otros tres Tribunales Superiores y basándose en las doctrinas del Tribunal Constitucional y del Tribunal Europeo de Derechos Humanos (TEDH), el Tribunal Superior de Andalucía admitió el derecho a oponerse a esta asignatura equiparándolo con el derecho a la objeción a cualquier asunto que pertenezca al "claustro íntimo de creencias" 2. Que un tribunal de ámbito menor y sin competencias para ello, enmendase la labor del Parlamento estatal constituía una decisión extraña, pero era el resultado de un conflicto que amenazaba con no ceder hasta que el Tribunal Supremo del Estado se pronunciase; hasta 2012 no se revocaron las sentencias y se defendió sin fisuras la constitucionalidad de la EpC. Además de negar el derecho a la objeción de conciencia, el tribunal afirmó que estas asignaturas no descansan en "concepciones relativistas ni asumen una posición respecto al género distinta de la que ya acoge el ordenamiento jurídico", que "tienen un profundo sentido moral pues pretenden inculcar en los alumnos los valores sobre los que descansan el orden público y la paz social, valores que asume la Constitución y parten del reconocimiento de la dignidad de la persona" y afirma que la Constitución obliga a los poderes públicos "a asegurar la enseñanza de esos fundamentos y limita el derecho reconocido a los padres por el artículo $27.3^{\prime 3}$.

\section{LA ESCALADA DE CONFLICTOS ENTRE LAS ADMINISTRACIONES EDUCATIVAS}

El veredicto del Tribunal Superior andaluz dio amparo y respaldo legal a las CC.AA. gobernadas por el PP. Las de Madrid y Valencia paralizaron la aplicación de la asignatura, admitieron el derecho a la objeción de las familias y elaboraron nuevas propuestas que en algunos casos habían sido rechazadas por otros tribunales autonómicos.

En la Comunidad Valenciana se adoptó una medida extravagante y conflictiva. El alumnado podría optar entre realizar un trabajo optativo de la materia o cursarla en inglés, ya que se denominaría Citizenship Education. Una sentencia de su Tribunal Superior la rechazó alegando que el alumnado que optase por realizar un trabajo, no accedía a todos los contenidos y objetos de la materia y no alcanzaría los objetivos exigidos. También rechazaba evaluar los conocimientos de inglés del alumnado, al no recoger el currículo de EpC, criterios de evaluación relacionados con la

\footnotetext{
${ }^{1}$ Artíulo 161 de la Constitución, desarrollado en el artículo 2.1 de la Ley Orgánica del Tribunal Constitucional.

${ }^{2}$ Sentencia de la Sala de lo Contencioso-Administrativo de Sevilla, Sección Tercera, 4 de marzo de 2008. Recuperado de https://www.iustel.com/diario_del_derecho/noticia.asp?ref_iustel=1027776[14 de marzo de 2019].

${ }^{3}$ Sentencia Administrativo Tribunal Supremo, Sala de lo Contencioso, Sección 7, Rec 6856/2010 de 12 de Noviembre de 2012. Recuperado dehttps://www.iberley.es/jurisprudencia/sentencia-administrativo-ts-sala-contencioso-sec-7-rec6856-2010-12-11-2012-9564441[14 de marzo de 2019].
} 
competencia en inglés ${ }^{4}$. Sin embargo, no impedía que la asignatura se impartiese en ese idioma, pues, según el Tribunal, el gobierno valenciano tenía competencia para establecer que una materia curricular se impartiese en inglés; pero ante la negativa del profesorado de Ciencias Sociales a hacerlo, se contrataron expertos en esa lengua que tradujesen lo que tenía que decir o viceversa.

La de Madrid aceptó la objeción de conciencia, dándole carácter optativo; el alumnado objector podría convalidarla con tareas de voluntariado en el centro escolar, en trabajos relacionados con lo establecido en el currículo de la comunidad, respecto a la Constitución Española o los Derechos Humanos. Como respuesta, el Ministerio sostenía que no cursar la asignatura tendría los mismos efectos que no cursar la de Matemáticas, e impediría la expedición de los títulos pertinentes.

La situación llevaba a un auténtico embrollo pedagógico, administrativo y judicial, sin visos de solución; confiando que los conflictos remitirían al pronunciase el Tribunal Supremo, cada vez se hacía evidente la necesidad de un consenso entre las fuerzas políticas, que hiciese viable una formación cívico-política. No obstante, determinados sectores de la sociedad española estaban más interesados en doblegar que en convencer, en imponer sus verdades amparados en el convencimiento de su infalibilidad, que en llegar al consenso.

\section{EL ARBITRAJE DEL TRIBUNAL SUPREMO}

En febrero de 2009, el Tribunal Supremo emitío cuatro sentencias sobre la materia $\mathrm{EpC}^{5}$ que dieron una respuesta clara y contundente a un debate deformado y forzado; venían a afirmar que:

a) Existen valores que configuran una ética común y constituyen el sustrato moral del sistema constitucional. Educar conforme a dichos valores éticos y a la moral que promueve, no constituye adoctrinamiento "es constitucionalmente lícita su exposición en términos de promover la adhesión a los mismos”.

b) Los poderes públicos están obligados a intervenir y garantizar una enseñanza que incorpore el "espacio ético común" y los valores que integran el sustrato moral del sistema constitucional. El alumnado debe recibirla sin distinción entre centros públicos o privados, y con independencia de sus convicciones ideológicas, religiosas o morales.

c) Se reconoce y acepta la existencia de concepciones diversas respecto a problemas sociales controvertidos, presentes en los contenidos de EpC y no procede censura alguna sobre ellos o ignorarlos irracionalmente.

d) Los contenidos curriculares deben ser tratados objetiva e imparcialmente por centros educativos y profesorado, sin incurrir en adoctrinamiento, dando cuenta de la diversidad de concepciones que existen sobre la realidad, sin presiones dirigidas a la captación de la voluntad del alumnado. La enseñanza de contenidos controvertidos, permitirá al alumnado someter a su reflexión y criterio personal las concepciones que existan sobre la problemática tratada.

e) Debe respetarse el derecho de las familias a elegir la formación religiosa y moral que estimen adecuada para sus hijos; católicas o no, creyentes o no. La conducta a seguir por profesorado y centros educativos, en la exposición de diferencias entre posturas, debe ser la de neutralidad sin que ello sea impedimento para abordarlas. De este modo el alumnado se encontrará situado ante una auténtica educación en valores, los valores de la conciencia

\footnotetext{
${ }^{4}$ Sentencia del Tribunal Superior de Justicia de la Comunidad Valenciana, Sala de lo Contencioso-Adminnistrativo Sección 2, de 24 de Julio de 2009. Recuperado de https://aicismo.org/data/docs/archivo_1034.pdf[14 de marzo de 2019].

${ }^{5}$ Sentencias que respondían a los Recursos 905, 1013, 948 y 949 de 2008, presentados por la Junta de Andalucía y el Principado de Asturias relativos a la negación del Derecho de Objeción de Conciencia ante la materia EpC y los DD. HH. Recuperado de https://www.iustel.com/diario_del_derecho/noticia.asp?ref_iustel=1033998[14 de marzo de 2019].
} 
crítica personal, el diálogo, la tolerancia y la convivencia que excluye la imposición de las ideas, antes que la reflexión sobre las mismas.

f) No existe el derecho a la objeción de conciencia frente a la EpC, ni posibilidad jurídica de establecer exenciones particulares para su no seguimiento por parte del alumnado cuya familia quisiera vivir conforme a su moral y religión particular; con exclusión de los valores comunes constitucionales y el contenido moral de la norma.

\section{LA “CONTRARREFORMA” DEL PP EN EPC}

En noviembre de 2011, el PP ganó las elecciones generales. En mayo de 2012, el nuevo Ministro, José Ignacio Wert, anunció en la Conferencia Sectorial de Educación que presentaría los cambios a introducir en las materias vinculadas con EpC que figuraban en la LOE.

Así y denominando a la nueva materia Educación Cívica y Constitucional, el PP cumplía una promesa del programa electoral asumido por Rajoy. Además de dar la razón a los sectores conservadores que sostenían el carácter adoctrinador de la EpC, afirmaba que el objetivo era eliminar las cuestiones controvertidas y susceptibles de adoctrinamiento ideológico de la materia más polémica de las últimas legislaturas.

En agosto de 2012, el Gobierno aprobaba un Real Decreto modificando el contenido de las asignaturas de $\mathrm{EpC}^{6}$. En lo fundamental, no añadían nada nuevo a lo anunciado por el ministro, pero recortaba los anteriores decretos, sustituyendo algunos contenidos por referencias genéricas, supuestamente menos comprometidas y reducía los contenidos más polémicos:

a) Suprimía la única mención a la homosexualidad del Decreto 1631/2006.

b) Eliminaba las cuestiones alusivas a conflictos o tensiones sociales, como actividades sociales que contribuyan a posibilitar una sociedad justa y solidaria.

c) Incluía conceptos como nacionalismos excluyentes, terrorismo, el papel de la iniciativa económica privada en la generación de riqueza o el respeto a la propiedad intelectual.

Para el MEC, el Real Decreto eliminaba la carga ideológica, suprimiendo lo planteado por el gobierno socialista para formar la conciencia en aspectos como: la identidad personal, la concepción de la familia, el matrimonio y la moral sexual. Se plegaba a las exigencias de quienes objetaban contra la materia y exigían al anterior gobierno excluir de sus contenidos las referencias a la moral, considerándola una cuestión que compete a las familias, y a la afectividad o rechazo a la discriminación de la homosexualidad. Además, presentaba otros aspectos no menos anecdóticos:

a) Uilizaba el masculino genérico, afirmando que incluía a las alumnas y a las compañeras.

b) Derivaba las cuestiones relativas a la mujer hacia el concepto de ser humano.

c) Cambiaba los contenidos afectivo-emocionales por los de libertad y responsabilidad, basados en la moral y valores católicos.

d) Sustituía el apartado relaciones interpersonales y participación por el de persona y sociedad.

e) Eliminaba las referencias a las desigualdades, reduciéndolas, exclusivamente, al marco constitucional.

f) Los pronunciamientos del anterior curriculum como "valoración crítica de la división social y sexual del trabajo y de los prejuicios sociales racistas, xenófobos, antisemitas, sexistas y homófobos", se sustituían por opciones menos comprometidas: "No

\footnotetext{
${ }^{6}$ Real Decreto 1190/2012 que modifica el Real Decreto 1513/2006, de 7 de diciembre, que establecía las enseñanzas mínimas de la Educación Primaria, así como el Real Decreto 1631/2006, de 29 de diciembre, que establecía las enseñanzas mínimas correspondientes a la ESO. Recuperado de https://www.boe.es/buscar/doc.php?id=BOE-A-201210473[14 de marzo de 2019].
} 
discriminación por razón de nacimiento, raza, sexo, religión, opinión o cualquier otra condición o circunstancia personal o laboral”.

El Real Decreto reavivaba la polémica, sus modificaciones resultaban insuficientes para los sectores ultraconservadores que reclamaban la eliminación de toda referencia a tan nefasta materia como calificaban a la EpC. Desde la prensa más conservadora se afirmaba:

(P) La regulación de los nuevos contenidos de la asignatura, ¿puede ser un paso previo para su supresión en la próxima reforma educativa?

(R) Ésa ha sido la intención del Ministerio, pero se podía haber ido mucho más lejos. Nadie ha quedado satisfecho. La asignatura está mal enfocada desde su origen porque se entendió más como una moral de Estado obligatoria que como un conjunto de conocimientos sobre el sistema democrático y constitucional. Por eso no basta con maquillarla. La mejor solución del conflicto es que el Gobierno cumpla su compromiso y quede suprimida en la nueva ley (Urcelay, 2012).

Para Profesionales por la Ética (2012), el cambio mantenía intactos su propósito y estructura de formar desde la administración de turno la conciencia moral del alumnado, evaluando si su comportamiento se ajustaba a los principios morales propuestos. Para ellos, la nueva EpC del PP:

a) Mantenía una moral de estado obligatoria

b) Pretendía formar las conciencias del alumnado

c) Perseguía modificar y evaluar comportamientos

d) Imponía criterios morales controvertidos en la sociedad española

e) Conculcaba el derecho primordial de las familias a educar a sus hijos e hijas

Quienes apoyaban la EpC no tardaron en reaccionar. El PSOE rechazó los cambios anunciados y las Consejerías de las Comunidades donde gobernaban, anunciaron que tomarían respuestas cuando se concretaran los nuevos Reales Decretos. La más enérgica vino de Andalucía, que promulgó una orden restituyendo aquellos contenidos suprimidos por el MEC ${ }^{7}$.

Los cambios introducidos fueron una primera andanada a la EpC, pero el ataque más profundo llegó con la Ley Orgánica de Mejora de la Calidad Educativa (LOMCE) que, presentada como una reforma de la LOE, introducía cambios que articulaban un nuevo marco educativo.

En 2013, se aprobó la séptima ley educativa de la democracia con el único apoyo del PP, tras numerosas protestas y acciones de rechazo: dos huelgas generales en la enseñanza y un pacto entre la mayoría de los grupos de la oposición que -excepto UPyD- se comprometieron a derogarla, paralizar inmediatamente su aplicación y trabajar para elaborar una nueva ley con el máximo consenso parlamentario y de la comunidad educativa.

Respecto a la EpC, la LOMCE explicita en su preámbulo su adhesión a la Recomendación del Comité de Ministros del Consejo de Europa a los estados miembros sobre la EpC Democrática de 2002; manifiesta que uno de los principios en los que se inspira el sistema educativo español es la transmisión y puesta en práctica de valores que favorezcan la libertad personal, la responsabilidad, la ciudadanía democrática, la solidaridad, la tolerancia, la igualdad, el respeto y la justicia, así como que ayuden a superar cualquier tipo de discriminación. Considera esencial la preparación para la ciudadanía activa y la adquisición de las competencias sociales y cívicas, recogidas en la Recomendación del Parlamento Europeo y del Consejo de diciembre de 2006 sobre las competencias clave para el aprendizaje permanente.

\footnotetext{
${ }^{7}$ Orden de 12 de diciembre de 2012 que modifica la de 10 de agosto de 2007, que desarrolla el currículo de Educación Primaria y ESO en Andalucía. BOJA, 21 de enero de 2013. Recuperado de https://www.juntadeandalucia.es/boja/2013/14/2 [14 de marzo de 2019].
} 
A la vez que desaparecía la EpC, se incluía -evaluable- la asignatura de Religión y se creaban dos nuevas asignaturas específicas denominadas Valores culturales y sociales para Educación Primaria y Valores éticos para ESO, a elección de las familias o tutores legales. Se suprimía la materia Educación Ético-cívica, sutituyéndose por Filosofía e Historia de la Filosofía.

\section{EL DiCTAMEN DEL CONSEJO DE ESTADO}

El Dictamen del Consejo de Estado sobre la EpC en el anteproyecto de la LOMCE, aunque se manifestaba a favor de la mayoría de sus aspectos legislativos, admitiendo la capacidad y potestad del gobierno para hacer este tipo de propuestas, era beligerante en aspectos que, aún siendo propuestas educativas, rozan cuando no alteran, el marco constitucional. Daba un varapalo a la propuesta del MEC, en lo referido a la enseñanza de la Religión o la segregación del alumnado por razones de sexo.

Respecto a la EpC, el Dictamen del Consejo hace una defensa de las materias relacionadas con la educación ético-cívica, subrayando el importante papel que, de acuerdo con el artículo 27.2 de la Constitución, desempeñan en la educación integral del alumnado y destaca la importancia de "adquirir competencias cívicas y sociales que garanticen conocimientos, capacidades y actitudes esenciales en relación con la democracia, con la justicia, igualdad, ciudadanía y derechos civiles”. Expone cómo el anteproyecto de ley elimina las cuatro asignaturas de la LOE vinculadas a esta materia, sustituyéndolas por dos asignaturas específicas de carácter obligatorio para los centros, pero no para el alumnado; Valores culturales y sociales y Valores éticos. Respecto a la primera, aconsejaba cambiar su denominación, ya que "en ningún caso deberían ser culturales sino éticos y sociales" ${ }^{8}$.

El Dictamen señalaba que el problema fundamental residía en que, al ser ambas asignaturas alternativas a la Religión, también obligatoria para los centros, se podría dar la circunstancia de que el alumnado que optara por Religión no estudiara -a lo largo de su formación obligatoria y postobligatoria- aquello que ahora se incluía en EpC. Con ello, se vulneraba lo antes apuntado del artículo 27 de la Constitución, además de los acuerdos suscritos con organismos internacionales, por lo que sugería ubicarla como asignatura obligatoria en algún momento.

El Dictamen sobre la exclusión de la EpC como asignatura obligatoria estuvo sujeto a numerosas interpretaciones. Los sectores más críticos con el gobierno celebraron el pronunciamiento, calificándolo de "enmienda, varapalo o revés” a la LOMCE, mientras que los más conservadores lo interpretaron como "aval o respaldo", subrayando que en él se veía la huella ideológica de Zapatero. La ex vicepresidenta María Teresa Fernández de la Vega, en su calidad de consejera vitalicia, responsable de la Sección que estudia los asuntos relacionados con el MEC, era la encargada de coordinar los trabajos jurídicos previos del borrador, sobre los que opinaron el resto de miembros de la Comisión Permanente. Las críticas obviaban que en la Comisión Permanente estaban, entre otros, el extesorero del PP y exministro de Sanidad, Romay Beccaría; Miguel Herrero de Miñón, uno de los siete “padres” de la Constitución de 1978, o el expresidente de UCD, Landelino Lavilla.

Ante el alud de críticas que provocó el Dictamen del Consejo de Estado sobre la anulación de la EpC, el Ministerio reaccionó estableciendo que el emprendimiento y la educación cívica y constitucional se trabajarían en todas las asignaturas de forma transversal.

\footnotetext{
${ }^{8}$ Dictamen 649/2012 de 19 de julio de 2012, p. 65 del Consejo de Estado. Recuperado de https://www.boe.es/buscar/ doc. php?id=CE-D-2012-649 [17 de marzo de 2019].
} 


\section{LOS RESULTADOS DE LA INVESTIGACIÓN Y SU DISCUSIÓN}

El análisis de los datos ha permitido centrarnos en cómo estos sectores utilizaron el espacio público y la batalla judicial, para frenar cambios en el curriculum y en la práctica educativa, perpetuando culturas escolares tradicionales, lo que nos priva del debate educativo de fondo: el modelo de sociedad y qué Educación para la Ciudadanía queremos

Los discursos articulados por los diferentes actores que protagonizaron la polémica, han permitido esbozar un complejo escenario político. Coincidimos con Cordero (2015) en que la asignatura constituyó un posicionamiento en defensa de los valores democráticos de participación y justicia social, pero que se redujo a una declaración de intenciones. Así lo constatan el escaso peso que se le dio en el curriculum, la laxitud con la que se aplicó y el reducido discurso generado para justificarla a medida que la polémica crecía.

Los términos en los que se gestó la polémica lo hacían irresoluble en esos momentos (Fernández-Soria, 2008). La investigación muestra cómo quienes actuaron desde sectores conservadores y tradicionales, lo hacían preocupados por mantener sus parcelas de poder y control de la moral pública, argumentando que constituía una intromisión en la moral privada. Una de ellas, considerada prioritaria, la de influir en la toma de decisiones curriculares oficiales con la consabida influencia que las tensiones en torno al curriculum tienen en la práctica educativa cotidiana.

Abordar las habituales contradicciones entre proyecto curricular, práctica educativa y conocimiento escolar, implica conocer lo que ocurre en el aula y fuera de ella (Merchán, 2001). En cambio, las investigaciones sobre el curriculum han descuidado el impacto que el discurso público puede tener en la práctica educativa y en la construcción de conocimiento escolar; con este artículo queremos contribuir a dar forma al primer peldaño de la escalera que nos permita llegar a tal propósito.

En su momento observamos con preocupación el conflicto generado (Gómez y García, 2013), compartiendo que el origen de la polémica era de carácter político e ideológico (Peinado, 2012; Valencia, 2013). Con este artículo hemos querido mostrar la complejidad y diversidad de agentes implicados, la mejor contribución que puede realizar una investigación de corte socio-histórico (Goodson, 2003), es arrojar luz a la polémica y tomar conciencia de cómo posterga cambios curriculares en la misma medida que perpetúa, sin cuestionarlos, los poderes que lo controlan. Conocer estas circunstancias resulta relevante en la toma de decisiones curriculares puesto que esta conlleva apostar por valores y creencias en conflicto que no puede estar exenta de una autoreflexión crítica para afrontar una práctica educativa consecuente con los principios pedagógicos que compartimos.

Como en el caso de los Social Studies (Evans, 2010), la polémica sobre la naturaleza de la Educación para la Ciudadanía, refleja los diferentes modelos de sociedad que defienden los actores implicados en ella. Si tuviéramos que realizar un balance de la polémica, ésta logró saldarse a favor de los sectores tradicionales y conservadores implicados en ella. La articulación de un discurso de la confrontación logró la supresión de la materia del curriculum escolar pero más importante aún es que postergara nuevamente el debate educativo.

Una de las lecturas más valiosas que podemos extraer de ello es que, tener voz en ese debate, como colectivo profesional que defiende la libertad de cátedra en una toma de decisiones curriculares bien informadas, puede ayudarnos a no escamoter el debate educativo a sus profesionales, para que tengan la oportunidad de profundizar en las ideas y teorías del curriculum.

La movilización contra la EpC utilizó elementos discursivos y emocionales que ganaron la batalla de la opinión pública por la incertidumbre, agotamiento y cansancio generados en casi una década (Muñoz, 2016). Una fuerte confrontación entre moral pública y privada que hace imposible un acuerdo mínimo sobre una ética pública y la secularización de la vida política (Cárcamo, 2012). No obstante, no queremos finalizar sin la esperanza de que en alguna ocasión, la cuestión de la educación se pueda abordar de manera sosegada, sin imposiciones, sin fundamentalismos y 
postulados pasados de época que recuerdan tiempos, afortunadamente, ya superados. En forma de pacto de estado por la educación o cualquier otra que concilie acuerdos duraderos.

Consideramos una cuestión de la mayor importancia para la sociedad española que se produzca un auténtico debate de ideas, que permita reflexionar y decidir sobre las posturas procedentes de todos los grupos políticos y no exclusivamente de las formuladas por alguno de ellos que las sustente en solitario y las imponga en función de su mayoría absoluta.

Será la única manera de conseguir una deseada estabilidad en el sistema educativo y no estar trabajando sobre bases poco sólidas que conducen, una y otra vez, a incesantes cambios educativos. En ello nos jugamos la formación de ciudadanas y ciudadanos, cómo no, también buena parte de nuestro futuro como país.

\section{Referencias}

Blanco, B. y García, R. (2007). Educación para la Ciudadanía: los contenidos inaceptables. Recuperado de http://www.objetamos.com/Documentos/11-EpC Los contenidos inaceptables.pdf [17 de agosto de 2014].

Cámara Villar, G. (2009). El debate sobre los valores en el currículo sobre Educación para la Ciudadanía y los Derechos Humanos. En V. Mayoral et al. La Sentencia. Educación para la Ciudadanía (pp. 47-62). Madrid: Wolters Kluwer.

Cárcamo Vásquez, H. (2012). Moral pública y moral privada: tensiones derivadas de la incorporación de la asignatura educación para la ciudadanía. Revista Pequén, 2(1), 125-147.

Carrillo, M. (2008). No es Objeción. Es oposición. Recuperado de https://elpais.com/diario/2008/05/23/sociedad/1211493601_850215.html [23 de mayo de 2008].

Carrillo Flores, I. (2011). La educación en valores democráticos en los manuales de la asignatura Educación para la Ciudadanía. Revista de Educación, nº extraordinario, 137-159.

Castro, M. (2007). La Educación para la Ciudadanía no es un catecismo socialista. El Confidencial, 11 de julio. Recuperado de https://www.elconfidencial.com/archivo/2007/07/11/73_manuel castro_secretario_general_educacion_ciudadania_catecismo_socialista.html [13 de marzo de 2019].

Conferencia Episcopal Española (2006). Orientaciones morales ante la situación actual de España. Recuperado de http://www.conferenciaepiscopal.es/documentos/Conferencia/Orientaciones SituacionActual.htm [17 de agosto de 2014].

Cordero, C. (2015). Educación para la ciudadanía. Una asignatura a debate: normativa, libros de texto y opiniones del profesorado, del alumnado y las familias (Tesis Doctoral). Madrid: UNED.

Escandel, J. J. (Coord.) (2009). La Educación para la Ciudadanía en los libros de texto. Madrid: CEU Ediciones.

EURYDICE (2005). La educación para la ciudadanía en el contexto escolar europeo. Bruselas: www.eurydice.org

Evans, R. W. (2004). The Social Studies Wars. What should we teach the children? Nueva York: Teachers College Press.

Evans, R. W. (2010). The Social Studies Wars, Now and Then. En W. C. Parker (ed.), Social Studies Today. Research and Practice (pp. 25-34). Nueva York: Routledge.

Fernández-Soria, J. M. (2008). Educación para la Ciudadanía y los derechos Humanos: Controversias en torno a una signatura (o entre ética pública y ética privada). Transatlántica de Educación, IV, 45-64.

Fernández Liria, P., Alegre Zahonero, L., Brieva, M. y Fernández Liria, C. (2007). Educación para la Ciudadanía. Democracia, capitalismo y estado de derecho. Madrid: Akal. 
García Ruiz, C. R. y Gómez Rodríguez, A. E. (2012). La idea de participación en los libros de texto de Educación para la Ciudadanía y los DD. HH. En N. de Alba, F. García Pérez y A. Santisteban (Eds.), Educar para la participación ciudadana en la enseñanza de las Ciencias Sociales (pp. 439-446). Sevilla: AUPDCS y Diada Editora.

García Roca, J. (2007). Educación para la Ciudadanía. Barcelona: Cristianisme i Justicia.

Garrido, J. Mª (2007). Educación para la Ciudadanía acentúa la división de la Iglesia. Redes Cristianas. Recuperado de http://www.redescristianas.net/2007/09/08/[8 de septiembre de 2007].

Gómez Rodríguez, A. E. (2008). Educación para la Ciudadanía: Una aproximación al estado de la cuestión. Enseñanza de las Ciencias Sociales, 7, 131-140.

Gómez Rodríguez, A. E. y García Ruiz, C. R. (2013). El Debate en torno a la Educación para la Ciudadanía en España. Una cuestión más ideológica que curricular. Enseñanza de las Ciencias Sociales, 12, 127-140.

González García, E. (2011). Ciudadanía, identidades complejas y cultura política en los manuales escolares andaluces de Educación para la ciudadanía y los derechos humanos (Tesis doctoral). Granada: Universidad de Granada.

Goodson, I. F. (2003). Estudio del curriculum. Casos y métodos. Buenos Aires: Amorrortu Editores.

Hernández Beltrán, J. C. (2009). A vueltas con Educación para la ciudadanía. Política y Pedagogía. Aula, 15, 175-200.

Jares, X. R. (2008). Los libros de texto. Cuadernos de Pedagogía, 380, 54-73.

Martín, I. (2007). Una propuesta para la enseñanza de la ciudadanía democrática en España. Madrid: Fundación Alternativas.

MEC (2004).Una Educación de Calidad para todos y entre todos: Propuestas para el debate. Madrid: MEC.

Merchán Iglesias, F. J. (2001). La producción del conocimiento escolar en la clase de Historia: profesores, alumnos y prácticas pedagógicas en la Educación Secundaria (Tesis Doctoral). Sevilla: Universidad de Sevilla.

Muñoz Ramírez, A. (2016). Movilización contra educación para la ciudadanía y los derechos humanos. Castilla-La Mancha, Castilla León y Madrid (Tesis doctoral). Salamanca: Universidad de Salamanca.

Papeles FAES (2007). El catecismo del buen socialista ¿Educación para la ciudadanía? Lo que Zapatero obliga a enseñar a nuestros escolares, 56. Recuperado de https://fundacionfaes.org/file_upload/publication/pdf/20130521164129el-catecismo-del-buensocialista.pdf [13 de marzo de 2019].

Peinado, M. (2012). En torno a la asignatura “Educación para la Ciudadanía”. Balance de una polémica (2009-2011). Revista de Antropología Experimental, 12, 277-286.

Peral Guerra, L. (2007). Educación para la ciudadanía o ingeniería social? Madrid: Universidad Francisco de Vitoria.

Profesionales por la Ética (2009). ¡Ni un paso atrás! La batalla de los padres frente a educación para la ciudadanía. Madrid: Criteria Club de Lectores.

Profesionales por la Ética (2012). La nueva Educación para la Ciudadanía del Partido Popular. Recuperado de http://profesionalesetica.org/wp-content/uploads/2012/06/Informe-EpCPP.pdf [14 de marzo de 2019].

Romero Morante, J. y Luis Gómez, A. (2003). La Historia del Curriculum y la Formación del Profesorado como encrucijada: por una colaboración entre la Historia de la Educación y una Didáctica Crítica de las Ciencias Sociales. Scripta Vetera. Recuperado de http://www.ub.edu/geocrit/sv-95.htm [8 de agosto de 2019].

Rouco Varela, A. M. (2007). La Educación para la Ciudadanía. Reflexiones para la valoración jurídica y ética de una asignatura en el sistema escolar español. Recuperado de: 
http://www.archimadrid.es/princi/menu/vozcar/framecar/conferencias/29052007.htm\#_ftnref1 $\underline{7}$ [2 de septiembre de 2008].

Savater, F. (2007). ¿Ciudadanos o feligreses? Recuperado de http://www.elpais.com/articulo/opinion/Ciudadanos/feligreses/elpporopi/20070704elpepiopi_ 5/Tes [13 de marzo de 2019].

Urcelay, J. (2012). Una materia adoctrinadora. Recuperado de https://www.larazon.es/historico/4087-analisis-una-materia-adoctrinadora-por-jaime-urcelayULLA_RAZON_487902 [14 de marzo de 2019].

Valencia Candalija, R. (2013). La implantación de Educación para la Ciudadanía en el sistema educativo español. Madrid: Dykinson.

Young, M. F. D. (ed.) (1971). Knowledge and Control.New Directions for the Sociology of Education. Londres: Collier-Macmillan.

\section{Cómo CITAR ESTE ARTÍ́CULO}

Gómez-Rodríguez, A.E. y García-Ruiz, C.R. (2019). Educación para la Ciudadanía en España. Una asignatura para la confrontación ideológica y política. Didáctica de las ciencias experimentales y sociales, 37, 51-66. DOI: 10.7203/DCES.37.14318 
